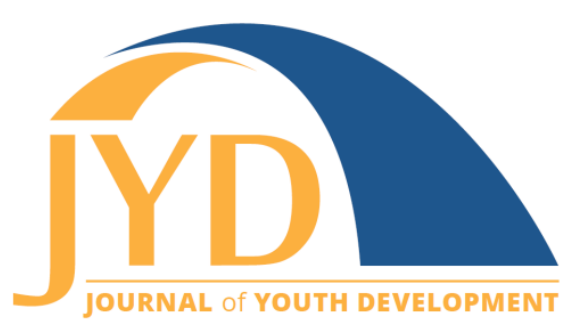

http://jyd.pitt.edu/ | Vol. 16 Issue 2-3 DOI 10.5195/jyd.2021.1113 | ISSN 2325-4017 (online)

\title{
How the Rubik's Cube Helps Explain the Evolving Approach to Effective Youth Development
}

\section{Michael McCabe}

U.S. Agency for International Development (USAID)

mimccabe@usaid.gov

\begin{abstract}
There is increased recognition that effective youth programming requires a Positive Youth Development approach that is multi-dimensional and intentional in terms of utilizing interventions that take into account age-appropriateness; socio-ecological considerations for youth, their families, and the local system; and that address the integrated needs of young people, rather than single-sector solutions. Addressing the complexity of this 3-dimensional integrated approach is key to putting into practice the findings of the Systematic Review of Positive Youth Development in Low- and Middle-Income Countries and helping develop thriving, resilient youth. The manuscript draws from recent USAID youth activities and research on the impact of youth engagement on development outcomes to provide a framework for new design considerations.
\end{abstract}

Key words: positive youth development (PYD), age-appropriate, multi-dimensional, integrated programming, socio-ecological, USAID, YouthPower Learning

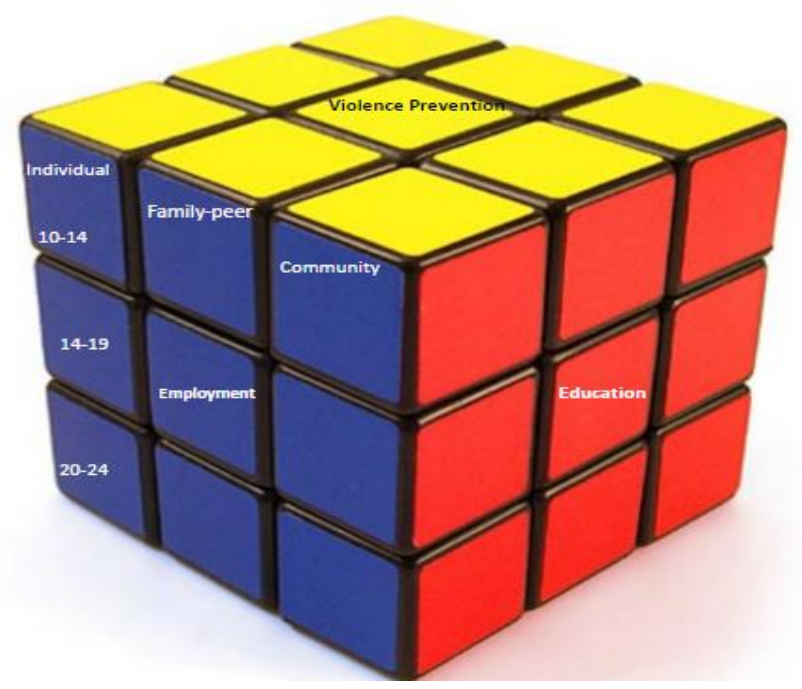

(cc) EY New articles in this journal are licensed under a Creative Commons Attribution 4.0 License. This journal is published by the University Library System, University of Pittsburgh and is cosponsored by the University of Pittsburgh Press. The Journal of Youth Development is the official peer-reviewed publication of the National Association of Extension 4-H Youth Development Professionals and the National AfterSchool Association. 


\section{The Rubik's Cube and Effective Youth Development}

After decades of donor-funded youth development programming that focused on a "one size fits all" approach for youth, recent research on positive youth development, or PYD as it is known, helps us refine and improve outcomes for all youth (Alvarado et al., 2017). PYD engages youth, families, communities, and systems to build the assets, healthy relationships, safe enabling environments, and opportunities to be agents of change for youth. Most importantly, PYD prompts USAID and other practitioners to take intentional, age-appropriate, socio-ecological, integrated approaches resulting in stronger youth outcomes and development outcomes. This approach, much like a Rubik's Cube, requires that we plan interventions along three dimensions.

1. Age-Appropriate: PYD-focused programming strives to consider how the specific realities and drivers associated with the four stages of youth: early adolescence (10 to 14 years), late adolescence (15 to 19), emerging adulthood (20 to 24), and transition to adulthood (25 to 29), relate to the various facets of development (physical, cognitive, social, emotional, and moral). This nuanced targeting of interventions draws upon the best practices of social norms and behavior change programming to leverage the dynamics and drivers of youth development to maximize outcomes. The Gender Roles, Equality, and Transformations (GREAT) Project in Uganda developed a package of evidence-based, scalable, life-stage tailored interventions to transform gender norms, reduce gender-based violence (GBV), and promote gender-equitable attitudes and sexual and reproductive health (SRH) among adolescents ages 10 to 19 in post-conflict communities (Institute for Reproductive Health, Georgetown University, 2016). The interventions, which are based on the socio-ecological model with a gender transformative perspective, were simple, low cost, compatible with community norms and values, and designed to be taken to scale. Most importantly, the activities were tailored to appropriate age-brackets for early adolescents and for older adolescents. GREAT led to significant improvements in attitudes and behaviors including positive changes in gender equality, partner communication, family planning use, and attitudes towards gender-based violence. As stated in their evaluation, "The greater change observed among males across all outcomes points to the opportunities for norm change around key life transitions of marriage and parenting as well as considerations of power underlying male access to interventions and media sources" (Institute for Reproductive Health, Georgetown University, 2016).

2. Socio-ecological: The second dimension of nuanced, intentional design requires that we look not only at interventions which focus on the individual youth, but those that 


\section{The Rubik's Cube and Effective Youth Development}

leverage the impact by peers and families, community institutions, and system-level factors such as laws, policies, or access to resources. An example is USAID's Proponte Más project in Honduras (USAID, YouthPower Action, 2019) which administers a youth services eligibility assessment and then provides youth and their families intensive family counseling and support. The project saw a 79\% decrease in young people's risk levels to be involved in violence and crime over the first year of their participation.

3. Integrated programming: The third dimension takes into account the need to understand youth as complex individuals with needs and desires, rather than a single priority such as employment. In the case of Alcance Positivo (Positive Reach) in Panama (USAID, 2013), a valuable lesson came after the first cohort of youth to go through a well-tested work preparedness curriculum and 3-month job placement suddenly were dropping out of the program at higher than expected levels. Discussions with participants revealed that, in addition to smaller than expected paychecks, many youth felt they had to leave their entry level jobs due to a mix of other issues they were dealing with including violence in the home or community, need for access to basic youth-friendly health services, and functional illiteracy. The project added a set of services and community mentors to accompany the participants with a significant improvement in outcomes.

Just as solving one side of a Rubik's Cube right does not guarantee the success of the overall puzzle, so we need to foster cross-sectoral design or linkages to complementary interventions to realize the full potential of any part of the program.

This nuanced, intentional approach may seem to create financial or planning challenges, yet evidence from YouthPower Learning's research on PYD in low- and middle-income countries substantiates when these considerations are taken into account, multiple cross-sector outcomes are a result for PYD programs (Alvarado et al., 2017). The illustrative interventions should incorporate as many of the seven key features of the PYD model as feasible (Alvarado et al., 2017). These components include assets and skills development, healthy relationship development, youth contribution as change-makers, access to safe spaces, promotion of a sense of belonging and pro-social norms, and access to youth-friendly services.

The integrated positive youth development program model faces coordination challenges at the design and implementation phases along with higher cost considerations and how to measure the most significant impacts of various attributes. USAID's YouthPower Learning systematic 


\section{The Rubik's Cube and Effective Youth Development}

review on PYD programs globally shows promising outcomes in building thriving youth, families, and communities. (Alvarado et al., 2017)

Importantly, PYD is not just a theoretical approach. It makes a difference in real young people's lives. The case of Carlos ${ }^{1}$ in Panama illustrates the imperative for the integration of PYD principles. Carlos' was a common story of the need for "second chances," within the USAIDfunded Alcance Positivo project in Central America. At age 5, Carlos' mother was forced to permanently leave him and his brother with their abusive, alcoholic father. Carlos started to drink at age 10, and joined a local gang at age 12 , which led to him being shot and left for dead at age 16. In this reality, Carlos lacked positive, healthy relationships, skills, and safe environments.

Pastor Manuel had just begun a USAID-funded youth outreach center which offered Carlos a second, or in his case, a fair first chance. Carlos started the basic literacy courses, using the computers in the center and even became a volunteer linked to the Youth Against Violence Movement. Carlos and the other youth (aged 10 to 24) in the center thrived in their self-esteem and confidence, and are an example of the complexity of youth, and youth development, that force us to adopt more nuanced approaches.

The Alcance Positivo project reached nearly 40,000 young people using a PYD approach to promote citizen security and livelihood development. The project developed a social norms campaign called the Power of 5 , as an organizing principle of five of the key PYD features to ensure that every youth, parent, teacher, community leader was committed to having (a) a caring adult mentor via mentoring and family communication programming, (b) skills training to find adequate employment, (c) the opportunity to be a changemaker in their community through municipal youth violence prevention councils and leadership programming, (d) access to youth-friendly services through the delivery of key tutoring and health services in their communities, and (e) safe spaces in non-school hours to help them develop in the form of community youth outreach centers. In addition to the mobilization of thousands of youth into civic action teams around violence prevention, mentoring younger youth, and employment, the project improved the sense of security in the 29 communities tracked by the evaluation from $34 \%$ to $62 \%$ in under 3 years (USAID, 2013).

\footnotetext{
${ }^{1}$ Name changed for privacy.
} 


\section{The Rubik's Cube and Effective Youth Development}

When combined, PYD approaches increase investment to truly move the needle on youth and technical outcomes and innovation. PYD is now being integrated both into sectoral programs such as food security programs in Uganda (USAID, 2019b), HIV/AIDS prevention activities through PEPFAR DREAMS Ambassador programming (USAID 2020), and also cross-sectorally via projects such as Puentes ("Bridges"; YouthPower Learning, 2019) in El Salvador that seek to address education, employment and violence outcomes with the evidence-based impact analysis of key soft skills on specific outcomes (Gates, et.al, 2016).

There is initial evidence that effective youth engagement can result in positive outcomes on global health, violence reduction, and economic growth (USAID, 2019a):

- Many health-related behaviors that arise during adolescence have implications for both present and future health and development (World Health Organization [WHO], 2014). Promoting youth behavior change with PYD components can have a triple dividend, bringing immediate benefits for youth as adolescents and positive effects on their future adult health (Gore et al., 2011). In turn, this positively impacts the health of future children (WHO, 2012).

- Adjusting health services, as age-appropriate, to offer young people privacy, to use neutral language, to reduce stigma, and to employ specially trained providers and health care staff in a whole-clinic approach, who are comfortable communicating on sensitive topics may increase service use among youth (Senderowitz et al., 2003).

- The connection of violence to youth is often linked to young people's access to education, employment, and sense of exclusion, indicating that failure to address the needs of young people may expose a country to greater risks of conflict emerging. To reintegrate young, underemployed ex-combatants, PYD-related programs have implemented programs to provide psychosocial counseling and training in soft skills and agriculture. Results showed that program participants spent fewer hours in illicit activities (Blattman \& Annan, 2011).

- Given the cumulative nature of human development, under-investments in youth are difficult to reverse later and can be passed on to the next generation. Failing to invest in youth risks economic costs resulting from negative outcomes such as early school dropout; young people trapped in unskilled, low paid jobs; high levels of underemployment; prolonged unemployment; substance abuse; and crime and violence. Countries that produce a skilled, healthy, and productive workforce are better positioned in the global economy to achieve economic prosperity, political stability, and social well-being. Investing in young people is important both because they make up a substantial share 
of the population of developing countries (youth bulge) and because enormous economic potential (youth dividend) can be realized through their full and productive employment in the workforce (Lancet Commission, 2016).

Investing effectively in youth is considered smart economics. The youth development field has made a significant evolution in the past few decades from a one-size-fits-all deficit-model focused on risks, to an assets-based approach with and for youth. Utilizing the three dimensions of age-appropriate stages, socio-ecological levels, and multi-sectoral nature of intentional design can help us unlock the puzzle of working successfully with youth, families, and communities to ensure thriving youth.

\section{Author Note}

The views expressed therein are those of the author and not necessarily those of USAID generally.

\section{References}

Alvarado, G., Skinner, M., Plaut, D., Moss, C., Kapungu, C., \& Reavley, N. (2017). A systematic review of positive youth development programs in low-and middle-income countries. YouthPower Learning, Making Cents International.

https://www.youthpower.org/sites/default/files/YouthPower/files/resources/SystematicReview\%2 OFINAL\%209-26-17\%20compress.pdf

Blattman, C., \& Annan, J. (2011). The impact of employment on high risk men in Liberia. Innovations for Poverty Action. https://www.poverty-action.org/study/ex-combatant-reintegration-liberia

Gates, S., Lippman, L., Shadowen, N., Burke, H., Diener, O., \& Malkin, M. (2016). Key soft skills for cross sectoral outcomes. USAID's YouthPower: Implementation, YouthPower Action. https://www.youthpower.org/resources/key-soft-skills-cross-sectoral-youth-outcomes

Gore, F., Bloem, P. J. N., Patton, G. C., Ferguson, J., Joseph, V., Coffey, C., Sawyer, S. M., \& Mathers, C. D. (2011). Global burden of disease in young people aged 10-24 years: A systematic analysis. The Lancet, 3779783), 2093-2102. https://doi.org/10.1016/S0140-6736(11)60512-6

Institute for Reproductive Health, Georgetown University (2016). GREAT Project endline report. Author. https://www.youthpower.org/resources/great-project-endline-report

Lancet Commission. (2016). Our future: Adolescent health and wellbeing. Author. https://www.thelancet.com/commissions/adolescent-health-and-wellbeing 
Journal of Youth Development | http://jyd.pitt.edu/ | Vol. 16 Issue 2-3 DOI 10.5195/jyd.2021.1113

The Rubik's Cube and Effective Youth Development

Senderowitz, J., Hainsworth, G., \& Solter, C. (2003, September 15). A rapid assessment of youth friendly reproductive health services. Technical Guidance Series, PathFinder International. http://www2.pathfinder.org/site/DocServer/YFS TG Final web version.pdf?docID=762

USAID.(2013) Alcance Positivo (Final Report). https://www.youthpower.org/resources/alcance-positivefinal-report

USAID. (2019a). Evidence on youth impact: Strengthening outcomes in global health, economic growth and security, stability and peacebuilding through investing in youth.

https://www.youthpower.org/resources/evidence-youth-impact-strengthening-outcomes-globalhealth-economic-growth-and-security-stability-and-peacebuilding-through-investing-youth

USAID. (2019b). Youth leadership agricultural activity empowers nearly 350,000 youth. https://www.usaid.gov/uganda/press-releases/usaids-youth-leadership-agriculture-activityempowers-nearly

USAID. (2020). DREAMS partnership to reduce HIV/AIDS in adolescent girls and young women. https://www.usaid.gov/global-health/health-areas/hiv-and-aids/technical-areas/dreams

USAID, Youth Power Action. (2019). Proponte más (Brief). https://www.youthpower.org/sites/default/files/YouthPower/files/resources/Proponte\%20Ma\%CC \%81s\%20Brief\%20Final.pdf

World Health Organization. (2012). Preconception care to reduce maternal and childhood mortality and morbidity (Meeting Report). Author.

World Health Organization. (2014). Health for the world's adolescents: A second chance in the second decade. Author.

YouthPower Learning. (2019). USAID bridges to employment. https://www.youthpower.org/Puentes 